\title{
Are the Dutch acquainted with and willing to try healthful food products? The role of food neophobia
}

\author{
B Schickenberg ${ }^{1, *}$, P van Assema ${ }^{1}$, J Brug ${ }^{2}$ and NK de Vries ${ }^{1}$ \\ 'Department of Health Education and Promotion, Maastricht University, PO Box 616, 6200 MD Maastricht, \\ The Netherlands: ${ }^{2}$ EMGO Institute, VU Medical Centre, Amsterdam, The Netherlands
}

Submitted 4 January 2007: Accepted 4 June 2007: First published online 9 August 2007

\begin{abstract}
Objectives: To assess participants' acquaintance with and willingness to try healthful food alternatives, and to test the psychometric properties of an adapted Dutch version of the Food Neophobia Scale (FNS) in order to study the role of food neophobia in this context.

Design: A cross-sectional study incorporating two web-based questionnaires, including a retest of the FNS one week later. Measures included acquaintance with and willingness to try 15 healthful food alternatives, level of food neophobia, level of education, gender and age. Multiple linear regression analyses were used to study associations between demographics and level of food neophobia as well as associations between level of food neophobia and acquaintance with and willingness to try the healthful alternatives.

Setting: The study was conducted in The Netherlands using a representative Internet panel.

Participants: A total of 326 participants aged 18-50 years participated.

Results: Internal consistency and test-retest reliability of the FNS version used were sufficient. On average participants were acquainted with 7.9 of the products and modestly willing to try the products. Lowly educated participants had significantly higher FNS scores than highly educated participants $(\beta=-0.23$, $P<0.01)$. FNS score was significantly associated with acquaintance with $(\beta=-0.21, \quad P<0.001)$ and willingness to try the healthful alternatives $(\beta=-0.26, P<0.001)$.

Conclusion: Further research into the role of food neophobia is warranted when wanting to stimulate the integration of healthful alternative products in the daily diet, especially among persons with low education.
\end{abstract}

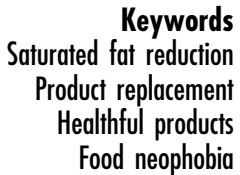

Keywords
Saturated fat reduction

Product replacement Food neophobia
High intakes of saturated fat and low intakes of fruit and vegetables $(\mathrm{F} \& \mathrm{~V})$ have been linked to increased risk for cardiovascular diseases ${ }^{1-3}$, various forms of cancer $^{2}$ and obesity $^{4-6}$. In The Netherlands, as in most Western countries, dietary recommendations have been issued indicating maximum recommended quantities of daily fat intake and minimal recommended intakes of $\mathrm{F} \& \mathrm{~V}^{7}$. National food consumption surveys in The Netherlands have shown that the average consumption of saturated fat and $\mathrm{F} \& \mathrm{~V}$ is not in accordance with these recommendations ${ }^{8}$. Changing the consumption of both fat and F\&V to the recommended levels is expected to yield substantial health benefits ${ }^{1,8-10}$.

The present study aimed to assess to what degree the Dutch are acquainted with and willing to try several healthful alternatives for food products. These healthful alternatives could contribute to a decrease of saturated fat intake and an increase of $\mathrm{F} \& \mathrm{~V}$ consumption if used on a regular daily basis. More specifically, the role of food neophobia in this context was studied as one's level of food neophobia has been shown to affect both the quality and the variety of foods in the diet ${ }^{11}$.

Margarine, full-fat cheese, butter, milk, pork meat, bakery goods and minced meat are examples of product groups contributing highly to the intake of saturated fat in the regular Dutch diet $^{12}$. In the last decades, the food industry has introduced alternatives with reduced fat contents for products in virtually every product group, e.g. meat substitutes, low-fat milk products, diet margarine and lean cheese.

In a simulation study it was shown that for most people the replacement of just a few daily used products high in saturated fat by healthful alternatives would help to reduce saturated fat intake in the daily diet to the recommended level ${ }^{13}$. Moreover, in another such study ${ }^{14}$ it was shown that participants using solely lean products 
in a certain product group were found to only partly compensate for the reduction of energy intake through fat by increasing their consumption of products from other product groups. In a field experiment, Gatenby et al. compared groups of female participants who consumed fat-reduced foods for a period of 10 weeks with a control group that consumed full-fat traditional products ${ }^{15}$. Results indicated that this method had short-term effects on energy balance by reducing intake of fat.

Low consumption of F\&V in the Dutch has been shown to be related to low perceived convenience of fresh $F \& V$ products $^{16}$. Therefore, fresh $\mathrm{F} \& \mathrm{~V}$ product alternatives with higher convenience have been introduced, e.g. F\&V juice with a prolonged shelf-life in comparison to fresh F\&V that contains a considerable percentage of the daily recommended amounts of $\mathrm{F} \& \mathrm{~V}$ and is packaged in an easy-to-transport ready-to-use container.

A crucial step in the process of incorporating new products into daily eating routines is that the new product needs to be tried a first time. For this to happen several situational and product-related prerequisites have to be met, such as the product must be available ${ }^{17}$ and appropriate for the time of day, meal or situation ${ }^{18}$ and the person must be willing to try the product.

A first testing and a first exposure to a product's taste are crucial for product acceptance and potential continuous use. Earlier studies on human food choice behaviour concluded that the personality trait of food neophobia may be a crucial determinant of people's willingness to try a new product ${ }^{19-27}$. Food neophobia has been defined as the avoidance of or reluctance to approach novel foods ${ }^{28}$. Pliner and Hobden developed a 10-item self-administered questionnaire called the Food Neophobia Scale (FNS) to reliably measure the degree of food neophobia and differentiate between food neophilics and neophobics, scoring at the lower or higher end of the spectrum, respectively ${ }^{23}$. The FNS was developed in Canada and has since been used in a number of studies in various Western countries such as the $\mathrm{USA}^{23}$, Sweden $^{21,29}$, Finland ${ }^{20}$, Australia $^{30}$, Belgium $^{31}$ and France $^{32}$. The personality variable is associated with reluctance to try new foods and is negatively correlated to familiarity ratings of food products.

Tuorila has proposed a distinction between five different categories of unfamiliar foods: functional foods, genetically modified foods, nutritionally modified foods, organic foods, and ethnic foods ${ }^{33,34}$. Referring to this categorisation, Pliner has argued that research does show that the FNS predicts willingness to try ethnic products, but not much evidence is available on products from other categories ${ }^{35}$.

In scientific databases no data were available on how acquainted the Dutch are with healthful alternatives for products typical in the Dutch diet and how willing they are to try these products. Moreover, the level of food neophobia in the Dutch population and the relationship between food neophobia and acquaintance with and willingness to try these kinds of products has not been studied before. Therefore, it is unknown whether participants' level of food neophobia has to be taken into account as a barrier in the process of stimulating the use of healthful alternative products.

The first purpose of the present study was to assess acquaintance with and willingness to try several products that can be used as more healthful or more convenient alternatives for regular food products, among Dutch adults. Second, we aimed to test the psychometric properties of a Dutch version of the FNS, and to assess respondents' level of food neophobia and possible subgroup differences. A third aim was to assess the association between level of participants' food neophobia and acquaintance with and willingness to try several healthful alternatives for traditional Dutch foods.

\section{Methods}

\section{Sample, design and procedure}

Respondents were members of a research panel of a Dutch Internet research agency (Flycatcher BV) consisting of about 12000 members. The panel is representative of Dutch society except for a slight overrepresentation of people from the province of Limburg (in the south of The Netherlands) and women. From this panel a stratified sample of 543 respondents was selected. We controlled for the variables gender, age (18-50 years), level of education and province of residence. The variable education was included in the regression analysis as a dummy variable. These persons were invited to participate in a study on food products and emailed the web address of an electronic questionnaire. Participants were reimbursed by the agency after completion of the questionnaire. A cross-sectional design was used, with the exception of the retest measure of the FNS for which participants were invited one week after completion of the first questionnaire. Respondents could not save their answers on their personal computer, nor was it possible to complete the questionnaire more than once. Respondents' answers were automatically saved on the central server into a data file. Participants were given a one-week deadline; it was not possible for respondents to enter the questionnaire after that date.

\section{Measures}

The first questionnaire included an adapted Dutch version of the $\mathrm{FNS}^{23}$ (Table 1). The FNS was translated into the Dutch language by a research group at Wageningen University. For the present study we introduced two changes in wording in response to comprehension problems encountered in an earlier unpublished study. FNS items were answered using a 7-point Likert scale format 
with answers ranging from 'I totally disagree' (1) to 'I totally agree' (7). Respondents' food neophobia score was computed by summing the answers of the 10 items, after reversing the scores of items 1, 4, 6, 9 and 10 (theoretical range 10-70).

In addition, respondents' acquaintance with and willingness to try 15 healthful alternatives was measured. The healthful alternatives (Table 2) consisted of 12 products containing less saturated fat than their traditionally used counterparts. These products included alternatives for meat products, full-fat cheese, solid frying fat, butter, sauce, snacks and dairy products, as these product categories highly contribute to the intake of saturated fat in the Dutch diet. Three products were included in the study as more convenient alternatives for no or low intake of fresh F\&V. These products included a fruit-based breakfast product, a fruit juice and a juice based on fruit and vegetables.

Two of the 15 products were selected based on the fact that they were not (yet) available in The Netherlands.

Table 1 The items of the Food Neophobia Scale

\begin{tabular}{cl}
\hline Item & \multicolumn{1}{c}{ Statement } \\
\hline (B) 1. & I am constantly sampling new and different foods \\
2. & I don't trust new foods \\
3. & If I don't know what a food is, I won't try it \\
(B) 4. & I like foods from different cultures \\
5. & Ethnic food looks too weird to eat \\
(B) 6. & At dinner parties, I will try new foods \\
7. & I am afraid to eat things I have never had before \\
8. & I am very particular about the foods I eat \\
(B) 9. & I will eat almost anything \\
(B) 10. & I like to try new ethnic restaurants \\
\hline
\end{tabular}

$(B)=$ scores were reversed for these items.
The remaining 13 products were purposefully selected from a wider selection of 51 products within the chosen product categories gathered during visits to several supermarket chains. Only products that could indeed be considered more healthful were selected, so products that e.g. over-compensated the decrease of fat with another unhealthful ingredient were excluded. The final selection included the products most unfamiliar to 64 participants of a pilot study. If products were more or less equally unfamiliar, the product lowest in saturated fat content was chosen. At least one product per product category was selected. One of the remaining two products was available in Dutch supermarkets one week after conducting the study, the last product was a lean chocolate bar available in Australia which was imported for this study. A pilot study among 64 participants indicated that the products were unfamiliar to most participants.

Front and side photographs of each product, as well as the product's name, were presented to participants alongside all questions. Acquaintance was measured with a single item per product ('I have seen the product before'; Yes/No). Willingness to try was measured by the item 'I would be willing to try the product' (5-point Likert scale from disagree $(-2)$ to agree $(+2)$ ). Both items were used in an earlier study of Tuorila et $a l^{26}$. A separate answer category was included for past consumption of the products. If participants indicated to have already tried a product their willingness to try the product was not measured and automatically set to the maximum $(+2)$, as past consumption was interpreted as evidence of willingness to try. An acquaintance sum score was calculated by summing the acquaintance scores of the 13 healthful alternatives available in Dutch supermarkets (range

Table 2 Overview of the healthful alternative products used in the study

\begin{tabular}{|c|c|c|}
\hline $\begin{array}{l}\text { Traditional products } \\
\text { in the Dutch diet }\end{array}$ & Healthful alternative & Product description \\
\hline Full-fat (Goudse) cheese & Uniekaas Zonnezuivel & $\begin{array}{l}\text { Cheese-like product from milk and sunflower oil which, compared } \\
\text { with full-fat 'Goudse' cheese, has } 40 \% \text { less total fat and } 50 \% \text { less } \\
\text { saturated fat }\end{array}$ \\
\hline $\begin{array}{l}\text { Whole or semi- } \\
\text { skimmed milk }\end{array}$ & Campina $0 \%$ vet melk & Fat-free 'skimmed' milk \\
\hline Coffee milk & Friesche Vlag Balance & Fat-free 'skimmed' coffee milk \\
\hline Yoghurt & Becel pro active & Fat-free yoghurt that helps to lower cholesterol \\
\hline Spread & $\begin{array}{l}\text { Van-Dijk Food products } \\
\text { Twenty four ultralight }\end{array}$ & Diet margarine with $20 \%$ fat, of which only $6 \%$ is saturated \\
\hline Butter & Blue band culinesse & $\begin{array}{l}\text { Lean liquid frying fat with fat content of } 82 \% \text {, of which } 30 \% \text { is } \\
\text { saturated }\end{array}$ \\
\hline Mayonnaise & Remia frites lijn & $\begin{array}{l}\text { Mayonnaise-like product with } 5.3 \% \text { total fat, of which } 0.8 \% \\
\text { saturated }\end{array}$ \\
\hline Meat & Quorn & Meat substitute based on soy beans \\
\hline Meat & Campina valess & Meat substitute based on milk, protein and seaweed \\
\hline Crisps/potato chips & Snack-a-jack & Puffed rice \\
\hline Biscuit & Bolletje zachte fruitkoek & Soft biscuit with $41 \%$ fruit and $9 \%$ total fat, of which $4 \%$ is saturated \\
\hline Fresh fruit & Hero Fruitontbijt & Drinkable breakfast based on fruit and fibre \\
\hline Fresh fruit & Hero Fruit 2 day & The equivalent of two pieces of fruit (juice and fibre) in a bottle \\
\hline Fresh fruit and vegetables & Knorr Vie Fruit shot & Fruit and vegetable pulp including banana, pumpkin and kiwi \\
\hline Chocolate bar & Mars lite & $\begin{array}{l}\text { Mars chocolate bar with } 30 \% \text { less fat than original Mars chocolate } \\
\text { bar (import from Australia, not available in The Netherlands) }\end{array}$ \\
\hline
\end{tabular}


0-13). Similarly, a willingness to try sum score was calculated by the mean of the individual scores of the 15 products (range -2 to +2 ).

Finally, the first questionnaire measured age, gender, country of origin and level of education. Due to differences in routing depending on the respondents' answers, the length of the questionnaire was maximally 96 items, but varied between respondents.

The second questionnaire consisted merely of the 10 FNS items.

\section{Data analysis}

Data were analysed using the SPSS 13.0 statistical package (SPSS Inc.). Possible selective dropout between (1) the invitation phase and actual enrolment in the study and (2) the two measurements was assessed using logistic regression analyses with dropout as dependent variable and age, sex and level of education as independent variables (as well as food neophobia score in the second dropout analysis).

The internal consistency of the adapted version of the Dutch FNS was assessed using Cronbach's $\alpha$ on both measurements; test-retest reliability was assessed with the Pearson correlation coefficient. Possible subgroup differences in level of food neophobia were analysed using linear regression analysis with level of food neophobia as the dependent variable and the demographic variables (age, gender and level of education) as independent variables.

To assess associations with level of food neophobia, stepwise linear regression analyses were conducted, with the acquaintance or willingness to try scores as dependent variables. To control for the possible influence of age, gender and level of education, these variables were included as independent variables in step 1 . In step 2 level of food neophobia was included as independent variable.

\section{Results}

\section{Response and sample characteristics}

Of the 543 panel members who were invited for this study 326 completed the first questionnaire (60.0\% response). No selective dropout occurred between the invitation phase and enrolment in the study. Participants' mean age was 32.8 years (standard deviation (SD) 8.7 years) and $56.4 \%$ were female. Of the participants $19.9 \%$ had a low level of education (none, primary school or lower vocational school), 38.3\% a medium level (secondary vocational school or high school degree) and $41.7 \%$ a high level (college or university degree). Of these 326 participants 274 completed the second questionnaire as well (84.1\% response). Between the two measurements also no selective dropout occurred.

\section{Acquaintance with and willingness to try bealthful alternatives}

The acquaintance sum score was 7.9 (SD 2.4), indicating that the participants on average had seen 7.9 of the 13 products before. The average willingness to try score across the fifteen products was 0.79 (range -2 to +2 , SD 0.78 ). For the individual products that were available in Dutch supermarkets at the time of the study, percentage acquaintance varied from $14.1 \%$ (alternative for butter) to 94.5\% (convenient alternative for fresh fruit at breakfast), and mean willingness to try score from -0.13 (low-fat alternative for full-fat coffee milk) to 1.35 (frying fat with reduced levels of saturated fat) (Table 3 ).

\section{Psychometric analysis of adapted version of Dutch FNS}

The internal consistency of the FNS was almost the same for the two measurements, i.e. $\alpha=0.81$ and 0.85 , respectively. The Pearson correlation coefficient for the FNS score between the two measurements was 0.81 . Due to the comparable results of the two measurements and the larger sample, it was decided to use the first measurement of the FNS for the remainder of the analyses.

\section{Level of food neopbobia and subgroup differences} The mean food neophobia score was 30.1 (range 11-63, SD 9.5). Low educated participants had a significantly higher food neophobia score (mean 32.5, SD 9.7) than participants with a high level of education (mean 28.2, SD 9.3) $(\beta=-0.23 ; P<0.01)$. No other significant differences in level of food neophobia for the tested demographic variables were found.

\section{Association between level of food neophobia and acquaintance with and willingness to try bealthful alternatives}

Gender was significantly associated with acquaintance with the healthful alternatives $(\beta=-0.27, P<0.001)$; women had seen more of the healthful alternatives than men. Furthermore, food neophobia score was inversely associated with acquaintance $(\beta=-0.21, \quad P<0.001)$. Gender $(\beta=-0.12, P<0.05)$ and food neophobia score $(\beta=-0.26, P<0.001)$ were also significantly associated with mean willingness to try the products. For the individual products significant associations were found between participants' level of food neophobia and their acquaintance with three and their willingness to try eight products (Table 3).

\section{Discussion and conclusions}

In the present study it was shown that on average participants were acquainted with the majority of a range of 
food products that can be regarded as healthful alternatives for regular products. On average, respondents were also rather willing to try these potentially healthful alternatives.

Acquaintance ratings of the healthful alternatives as well as mean willingness to try scores appeared higher than in comparable studies, which however mainly used different kinds of products than the present study. The majority of studies on the relationship between level of food neophobia and behaviour towards unfamiliar food products have used ethnic foods ${ }^{26,36-39}$. The fact alone that we used products from frequently used product groups might explain the higher acquaintance ratings. Furthermore, we presented participants with unaltered information about the products depicting real product names and in most cases brand names as well. Some other studies have used fake product names or product descriptions to decrease familiarity $3,26,40-42$ or presented stimuli in plastic cups instead of their original packaging $^{20,43}$. The Internet format of the present study might be another explanation for the comparably high willingness to try scores as the study did not include (the risk of) actual tasting of the products as was included in other studies ${ }^{20,41,43,44}$. The surprisingly high reported acquaintance with one of the products not available might be due to the high similarity of the package, in terms of colour, font and proportions, with the original Mars chocolate bar available in The Netherlands.

The psychometrical qualities of the adapted Dutch version of the FNS were sufficient ${ }^{45,46}$ and comparable with those of other studies reporting internal consistency and/or test-retest correlation of translations of the original scale ${ }^{26,31}$. In the present study we did not validate the FNS against neophobia measures in the laboratory as had been done in Pliner and Hobden's original work ${ }^{23}$; therefore we cannot say anything about the true validity of the adapted Dutch version of the FNS.

Mean level of food neophobia in the sample seems comparable to that found in earlier studies in participants of roughly comparable ages ${ }^{26}$. However, Ritchey et al. warn against cross-nationally comparing results acquired with the FNS before it has been ultimately proven that this scale is transnational, thus reliably measuring the same concepts in different languages/cultures ${ }^{47}$. In the present study we did not find significant gender or age differences in level of food neophobia. Differences between level of food neophobia in men and women have been reported in three studies from Scandinavia where men were found to score higher ${ }^{21,26,33}$. Other studies did not report such differences between men and women $^{11,19,23,29,48-50}$. Several studies report age differences in level of food neophobia ${ }^{21,25,26,29,36,51,52}$, whereas others do not ${ }^{11,53}$. Many studies support the notion that one's level of food neophobia decreases as age increases $^{26}$. As Cooke et al. put it: "Food neophobia appears to be minimal in infancy, raising rapidly at age 
two and gradually tailing off thereafter ${ }^{51}$. The absence of an effect of age on level of food neophobia in the present study might therefore be explained by the chosen age range in the study sample (18 to 50 years), omitting the very young and the elderly. To our knowledge two earlier studies have looked into the relationship between socioeconomic status (SES) and level of food neophobia. Our finding of a significant relationship between level of education and food neophobia scores replicates results of a study in Finland ${ }^{26}$ which used participants' level of education as a proxy for SES. However, Flight et al. were not able to show significant relationships between their proxies for SES (two household indices) and food neophobia scores ${ }^{30}$.

As in related studies, we were able to show significant, though small, negative associations between level of food neophobia and both acquaintance with and willingness to try the presented food products. In the present study, however, for the first time these findings were replicated using only products from, in Tuorila's terms, the category of nutritionally modified foods and for F\&V products with improved convenience ${ }^{34}$. Women were significantly more acquainted with and willing to try the healthful alternatives. These results are consistent with the findings of Tuorila et $a{ }^{26}$ and are likely to be resulting from differences in exposure to food products through food preparation ${ }^{21}$.

In interpreting our findings, it should be kept in mind that the items used to measure acquaintance with and willingness to try were based on items used in other studies, but information on the reliability and validity of these items is lacking, and both concepts were measured using only a single item for each concept. Face validity of the acquaintance item is judged to be high as participants were asked to remember whether they had seen a product before on the basis of the product name and a picture of each product. Another factor that might have influenced the results of the present study is the selection of the 15 products from the broader range of available products of interest, i.e. healthful alternatives for traditional foods in the Dutch diet. We do not know how much this influenced the results because we do not know whether the role of food neophobia differs for each product or each product category (or even broader categories), as the study only included one or two products per product category. Furthermore, we did not control for possible confounders that could have influenced the association between food neophobia and both acquaintance with and willingness to try the products. It therefore is possible that the found associations might be attributed to third variables, for instance a personality characteristic, and might be overestimated. Finally, since this study was conducted in a sample of 18-50-year-olds results are not to be generalised to other groups in Dutch society.

To overcome some of the limitations of the present study, further research should try to include some possi- ble confounders in the design and also include actual tasting of the unfamiliar food products as an outcome variable.

Despite the study limitations and the modest associations that we found, we conclude that our study results indicate that a person's level of food neophobia might be a factor worth accounting for when wanting to introduce foods in the diet one is not acquainted with. This seems to hold especially true for the low educated group, because this group has the greatest need for behavioural change with respect to diet ${ }^{54}$, on the one hand, and has been shown to be affected most by food neophobia, on the other. Literature suggests a number of strategies to reduce the level of food neophobia to alter food choice behaviour regarding unfamiliar foods, e.g. taste information $^{27,36,38,41}$, repeated exposure ${ }^{27}$ and social modelling ${ }^{19}$. At the least, our study shows the need for further investigation of the role of food neophobia, to explore whether the use of such strategies in health education interventions focusing on integration of healthful alternatives in the daily diet is indeed promising to accomplish health gain.

\section{Acknowledgements}

Sources of funding: The study was financed by the Netherlands organisation for health research and development (ZonMw). This paper was conceived and written independently of the funding agency. The funding agency had no role in the study design, data collection, analysis, interpretation, writing, or decision to submit the manuscript for publication.

Conflict of interest declaration: There are no conflicts of interest.

Authorship responsibilities: B.S. and P.v.A. conceived the study hypothesis, supervised data analyses and wrote the manuscript. All co-authors made substantial contributions to data analysis and interpretation and the writing of the manuscript.

Acknowledgements: We thank Annet Hoek and Kees de Graaf of Wageningen University for giving their permission to let us use and alter their Dutch translation of the food neophobia scale for this study.

\section{References}

1 Hooper L, Summerbell CD, Higgins JPT, Thompson RL, Capps NE, Smith GD, et al. Dietary fat intake and prevention of cardiovascular disease: systematic review. British Medical Journal 2001; 322: 757-68.

2 Fung TT, Willett WC, Stampfer MJ, Manson JE, Hu FB. Dietary patterns and the risk of coronary heart disease in women. Archives of Internal Medicine 2001; 161: 1857-62.

3 Hu FB, Rimm EB, Stampfer MJ, Ascherio A, Spiegelman D, Willett WC. Prospective study of major dietary patterns and risk of coronary heart disease in men. American Journal of Clinical Nutrition 2000; 72: 912-21. 
4 Steinmetz KA, Potter JD. Vegetables, fruit, and cancer prevention: a review. Journal of the American Dietetic Association 1996; 96: 1027-39.

5 Alavanja MCR, Brown CC, Swanson C, Brownson RC. Saturated fat intake and lung cancer risk among nonsmoking women in Missouri. Journal of the National Cancer Institute 1993; 85: 1906-16.

6 Willett WC. Diet, nutrition, and avoidable cancer. Environmental Health Perspectives 1995; 103: 165-70.

7 Health Council of the Netherlands. Dietary Reference Intakes: Energy, Proteins, Fats and Digestible Carbohydrates (No. 2001/19). The Hague: Health Council of the Netherlands, 2001.

8 Hulshof KFAM, Ocké MC, Drijvers JJMM, Van Rossum CTM, Buurma-Rethans EJM, Brants HAM, et al. Resultaten van de voedselconsumptiepeiling 2003. Publication No. 350030002/2004. Bilthoven: RIVM, 2004.

9 Ammerman AS, Lindquist $\mathrm{CH}$, Lohr KN, Hersey J. The efficacy of behavioral Interventions to modify dietary fat and fruit and vegetable intake: a review of the evidence. Preventive Medicine 2002; 35: 25-41.

10 Mokdad AH, Bowman BA, Ford ES, Vinicor F, Marks JS, Koplan JP. The continuing epidemics of obesity and diabetes in the United States. JAMA: Journal of the American Medical Association 2001; 286: 1195-200.

11 Falciglia GA, Couch SC, Gribble LS, Pabst SM, Frank R. Food neophobia in childhood affects dietary variety. Journal of the American Dietetic Association 2000; 100: 1474-81.

12 Van den Brandt PA, Van de Crommert S, Mordant A. De bijdrage van voedingsmiddelen aan de consumptie van macro- en micronutrienten door de Nederlandse bevolking. Maastricht: Maastricht University, 1990.

13 Morgan R, Sigman-Grant M, Taylor DS, Moriarty K, Fishell V, Kris-Etherton PM. Impact of macronutrient substitutes on the composition of the diet and the US food supply. Annals of the New York Academy of Sciences 1997; 819: 70-95.

14 Kistemaker C, Löwik MRH, Wedel M, Hulshof KFAM Compensatiemechanismen met betrekking tot de consumptie van vetarme produkten bij 22-49 jarige mannen. Voedselconsumptiepeiling 1987-1988 (No. V91.093). Zeist: TNO-Voeding, 1991.

15 Gatenby SJ, Aaron JI, Morton GM, Mela DJ. Nutritional implications of reduced-fat food use by free-living consumers. Appetite 1995; 25: 241-52.

16 Brug J, Lechner L, De Vries H. Psychosocial determinants of fruit and vegetable consumption. Appetite 1995; 25: 285-96.

17 Mela DJ. Food choice and intake: the human factor. Proceedings of the Nutrition Society 1999; 58: 513-21.

18 Furst T, Connors M, Bisgogni CA, Sobal J, Winter Falk L. Food choice: a conceptual model of the process. Appetite 1996; 26: 247-66.

19 Hobden K, Pliner P. Effects of a model on food neophobia in humans. Appetite 1995; 25: 101-13.

20 Arvola A, Lähteenmäki L, Tuorila H. Predicting the intent to purchase unfamiliar and familiar cheeses: the effects of attitudes, expected liking and food neophobia. Appetite 1999; 32: 113-26.

21 Hursti UK, Sjödén P. Food and general neophobia and their relationship with self-reported food choice: familial resemblance in Swedish families with children of ages 7-17 years. Appetite 1997; 29: 89-103.

22 Pliner P, Eng A, Krishnan K. The effects of fear and hunger on food neophobia in humans. Appetite 1995; 25: $77-87$.

23 Pliner P, Hobden K. Development of a scale to measure the trait of food neophobia in humans. Appetite 1992; 19: 105-20.

24 Raudenbush B, Frank RA. Assessing food neophobia: the role of stimulus familiarity. Appetite 1999; 32: 261-71.
25 Raudenbush B, Schroth F, Reilley S, Frank RA. Food neophobia, odor evaluation and exploratory sniffing behaviour. Appetite 1998; 31: 171-83.

26 Tuorila H, Lähteenmäki L, Pohjalainen L, Lotti L. Food neophobia among the Finns and related responses to familiar and unfamiliar foods. Food Quality and Preference 2001; 12: 29-37.

27 Tuorila H, Meiselman HL, Bell R, Cardello AV, Johnson W. Role of sensory and cognitive information in the enhancement of certainty and liking for novel and familiar foods. Appetite 1994; 23: 231-46.

28 Birch LL, Marlin DW. I don't like it; I never tried it: effects of exposure to food on two-year-old children's food preferences. Appetite 1982; 4: 353-60.

29 Koivisto U, Sjödén P. Food and general neophobia in Swedish families: parent-child comparisons and relationships with serving specific foods. Appetite 1996; 26: $107-18$.

30 Flight I, Leppard P, Cox DN. Food neophobia and associations with cultural diversity and socio-economic status amongst rural and urban Australian adolescents. Appetite 2003; 41: 51-9.

31 Eertmans A, Victoir A, Vansant G, Van den Bergh O. Foodrelated personality traits, food choice motives and food intake: mediator and moderator relationships. Food Quality and Preference 2005; 16: 714-26.

32 Nicklaus S, Boggio V, Chabanet C, Issanchou S. A prospective study of food variety seeking in childhood, adolescence and early adult life. Appetite 2005; 44: 289-97.

33 Bäckström A, Pirttilä-Backman A-M, Tuorila H. Dimensions of novelty: a social representation approach to new foods. Appetite 2003; 40: 299-307.

34 Tuorila H. Keeping up with the change: consumer responses to new and modified foods. Food Chain 2001; 38-40.

35 Pliner P. Consumer responses to novel and 'functional foods'. Abstract of an oral presentation to Xth Food Choice Conference, Wageningen, The Netherlands, 30 June-3 July 2002.

36 McFarlane T, Pliner P. Increasing willingness to taste novel foods: effects of nutrition and taste information. Appetite 1997; 28: 227-38.

37 Meiselman HL, Schutz HG. History of food acceptance research in the US Army. Appetite 2003; 40: 199-216.

38 Pelchat ML, Pliner P. 'Try it You'll like it.' Effects of information on willingness to try novel foods. Appetite 1995; 24: 153-65.

39 Pliner P, Martins Y. The effects of meal cues and amount consumed on predictions of future eating in others. Personality and Social Psychology Bulletin 2002; 28: 1354-65.

40 Potts HWW, Wardle J. The list heuristic for studying personality correlates of food choice behaviour: a review and results from two samples. Appetite 1998; 30: 79-92.

41 Martins Y, Pelchat ML, Pliner P. 'Try it; it's good and it's good for you': effects of taste and nutrition information on willingness to try new foods. Appetite 1997; 28: 89-102.

42 Pliner P, Pelchat M, Grabski M. Reduction of neophobia in humans by exposure to novel foods. Appetite 1993; 20: 111-23

43 Martins Y, Pliner P. Human food choices: an examination of the factors underlying acceptance/rejection of novel and familiar animal and nonanimal foods. Appetite 2005; 45: 214-24.

44 Pliner P, Pelchat ML. Neophobia in humans and the special status of foods of animal origin. Appetite 1991; 16: 205-18.

45 Nunnally JC, Bernstein IH. Psychometric Theory, 2nd ed. New York: McGraw-Hill, 1994 
46 Spector PE. Summated Rating Scale Construction: An Introduction. Newbury Park, CA: SAGE Publications, 1992.

47 Ritchey PN, Frank RA, Koivisto Hursti U-K, Tuorila H. Validation and cross-national comparison of the food neophobia scale (FNS) using confirmatory factor analysis. Appetite 2003; 40: 163-73.

48 Pliner P. Development of measures of food neophobia in children. Appetite 1994; 23: 147-63.

49 Rigal N, Frelut M-L, Monneuse M-O, Hladik C-M, Simmen B, Pasquet P. Food neophobia in the context of a varied diet induced by a weight reduction program in massively obese adolescents. Appetite 2006; 46: 207-14.

50 Wardle J, Carnell S, Cooke L. Parental control over feeding and children's fruit and vegetable intake: how are they related? Journal of the American Dietetic Association 2005; 105: 227-32.

51 Cooke L, Wardle J, Gibson EL. Relationship between parental report of food neophobia and everyday food consumption in 2-6-year-old children. Appetite 2003; 41: 205-6.

52 Pliner P, Loewen ER. Temperament and food neophobia in children and their mothers. Appetite 1997; 28: 239-54.

53 Addessi E, Galloway AT, Visalberghi E, Birch LL. Specific social influences on the acceptance of novel foods in 2-5 year old children. Appetite 2005; 45: 264-71.

54 Van der Lucht F, Picavet HSJ. Sociaal-economische verschillen in leefstijl. Bilthoven: RIVM, 2006. 